\title{
Discussion on the Training Model of College Students' Scientific Research and Innovation Ability through Tutorial System

\author{
Xiao Shoubai
}

(NanChang Institute of Science and Technology, Nanchang,330108)

Keywords: Tutorial system; University students; Research innovation; Model training

\begin{abstract}
The tutorial system is a student guidance system based on individual guidance. It is an important supplement to the class teacher and counselor system. Promoting the mentoring system is an inevitable requirement for implementing personalized education and promoting credit system reform, and it is also conducive to cultivating scientific research and innovative talents with innovative spirit and practical ability. The excellent student tutoring system is an effective implementation form of the tutoring system. The implementation of the outstanding student tutoring system is a breakthrough in advancing the tutor system. This article comprehensively uses the related theories of pedagogy, psychology, and management, uses literature analysis, investigation and analysis, comparative research and other methods. Starting from the analysis of the characteristics of the tutorial system, this paper clarifies the advantages of the tutorial system in cultivating college students' scientific research and innovation capabilities. The implementation of the excellent student tutor system has important influence on the promotion of the tutor system, discussed the implementation status of the excellent student tutor system in China, and discussed how to optimize the implementation process of the undergraduate excellent tutor system and promote the cultivation of innovative personnel.
\end{abstract}

\section{Introduction}

The college student tutor system is a new type of education management model. Different from the graduate tutoring system, the college tutoring system refers to the teacher's individual education system that provides individual guidance on the study, morality, ideology, and employment of college students through the use of words and deeds to improve students' ideological and moral levels, scientific and cultural levels, and research and innovation capabilities. Quality. Provided institutional conditions, undergraduate tutoring system is a strong guarantee for the provision of personalized education under the current credit system conditions; college student tutoring system has "according to their aptitude, individualized education; academic guidance as the main line, comprehensive quality training; advocating teachers and students Interaction, stimulate students' subjectivity; emphasis on teacher-student interaction, and create a harmonious relationship between teachers and students; etc.; implementation of college student tutor system can promote the growth of innovative talents from knowledge structure, innovation ability, innovation personality and many other aspects. This paper aims at the problem of insufficient scientific research innovation capacity of college students. The introduction of a scientific research tutor system at university colleges and universities, which allows experienced tutors to lead students to actually participate in research projects, can not only improve college students' technological innovation ability and knowledge, but also improve scientific research strength. Finally, some suggestions and countermeasures are proposed to further improve the scientific research and innovation ability of college students.

\section{Advantages of College Student Tutoring System in Training Scientific Research and Innovative Talents}

As an important supplement to the student guidance system under the credit system, the college student tutoring system can play an active role in promoting personalized education and cultivating innovative talents. A large number of practices at home and abroad have proved that the college student tutor system is an inevitable requirement for the implementation of personalized education 
and the reform of the credit system, and is also conducive to cultivating innovative talents with scientific research innovation spirit and practical ability. Combined with the discussion of the characteristics of the college student tutor system, we believe that compared with the college class teacher and counselor system, the college student tutor system has obvious advantages in cultivating innovative talents. This is mainly reflected in the following two aspects.

\section{Conducive to the optimization of students' knowledge structure}

Knowledge structure is the organization of various kinds of knowledge in the human brain. It involves a variety of factors such as the proportion of knowledge in various disciplines, the degree of correlation, and the synergy. A reasonable knowledge structure is the basis for innovative activities. Training innovative talents should begin by optimizing students' knowledge structure. Under the mentoring system, the distance between the tutor and the student is getting closer, and the tutor has more opportunities to contact, understand and master the student's personality, interests, hobbies, specialties and development "advantage zone". Based on this, the tutor will work out for each student. The appropriate training program will provide students with targeted and personalized learning guidance and guide them to gradually improve their knowledge structure.

\section{Helping to strengthen students' creative ability}

Innovation ability is the ability to solve problems creatively, and its core is scientific research and innovative thinking ability. The ability of scientific research and innovation requires innovators to make unprecedented leaps on the basis of their predecessors. Whether or not they have scientific research and innovative thinking ability is a fundamental condition for one's ability to innovate. The tutorial system is a face-to-face individual instruction system for teachers and students, which can provide favorable conditions for students' creative abilities.

\section{The Connotation and Training Phase of the Tutorial System}

At present, nearly one hundred colleges and universities in China are piloting the college student tutoring system. The so-called college student tutoring system refers to the backbone teachers and students who organize scientific research and teaching under the premise of a two-way teacher-student relationship, and serves as an instructive teacher for college students to study, life, morality, and psychology of students. Individual instructional teaching systems are used to teach students in accordance with their aptitude, help students understand the training program of the school's professional talents, formulate their own learning and ability development plans and future career plans, and give full play to their own strengths and strengths to improve their own comprehensiveness. Quality and ability to adapt to society. The implementation of university students' title system lies in the interaction and opening, integration and innovation, and the promotion of the improvement of teaching quality. It is an effective way to cultivate the scientific research and innovation ability of university students. The training mode of students' innovative ability under the mentoring system is generally divided into four stages: the entry stage for freshmen, the basic training stage, the project participation stage, and the innovative practice stage. These four stages are formulated according to the students' cognitive laws and the training cycle of innovation ability, and they are systematic and continuous.

\section{Freshmen entering the school stage}

Through the publicity and education at the beginning of the school year, students are encouraged to love this major and inspire students' enthusiasm to participate in scientific research work. Students are encouraged to participate in scientific research work and cultivate students' spirit of innovation. At the same time, the construction of laboratory software and hardware environment will be strengthened to create favorable experimental and learning conditions for university students and lay a foundation for further participation in scientific research.

\section{Basic training stage}

This stage is a key stage for the improvement of students' own business abilities. Learning and mastering solid basic skills and professional theoretical knowledge will lay the foundation for further scientific research. At the same time, students are encouraged to participate in scientific research work and listen to lectures on relevant professional subjects. This will stimulate students' 
interest in a particular field and focus on cultivating students' sense of innovation.

\section{Project participation stage}

The first two phases are the foundation for students' participation in scientific research. At this stage, students are able to select their own research fields and fully participate in scientific research work, with the help of their tutors, in combination with their own conditions. This stage should fully reflect the role of the tutor, select reasonable research topics for students, and develop a reasonable research plan. In accordance with the principle of gradual and orderly progress, the tutor gives students a choice of moderate difficulty, clear direction, and specific topics, inspiring students' subjective initiative, encouraging college students to participate in scientific research activities, and improving overall quality.

\section{Innovative practice period}

This stage is a stage that embodies the students' overall quality and comprehensive ability. In combination with graduation design and various types of science and technology competitions, students' creative abilities are comprehensively improved, and students are trained to master correct innovation methods and have the ability to analyze problems and solve problems autonomously. At the same time, college students are about to move toward social work positions. After years of research and innovation at the university, they have basically mastered innovative methods and innovative skills, can independently complete scientific research work, and laid a solid foundation for the individual's further development.

\section{College Student Tutor System Training Model}

Improve the construction of mentor team is an important condition for the tutorial system

Strengthening the construction of the mentor team is an important condition for the tutorial system. First of all, it is necessary to perfect the training mechanism for the mentor team. Through intensive learning, experience exchanges, problem discussions, and mutual learning visits by sister colleges, etc., it is possible to conduct planned training for tutors, improve their professional theoretical level, and guide their students' practical ability to conduct research projects. Second, high-level experts and scholars outside the university can be selected as mentors.

Inspiration of student expertise and careful selection of topics is the key to developing tutorial systems

Each student has his own interest and expertise, and the mentor also has their own professional and research areas. This requires that in the development of the mentoring system, first of all, it is necessary to achieve "two-way choices" between teachers and students to ensure that students choose their tutors according to their own interests and wishes. Instructors should fully demonstrate the innovation, application, and feasibility of the topic and select topics that have research value in order to stimulate students' interest and improve their overall abilities.

The establishment of a sound assessment system is the fundamental development of the tutorial system

The school must ensure the implementation of the tutorial system from the system, and focus on strengthening the construction of the mentor assessment system and incentive mechanism. On the one hand, it is necessary to improve the assessment system: the main basis for the assessment is the scientific research and guidance work plan, the guidance and completion of the students on a regular basis, the guidance of the work summary and the students' performance and achievements. Second, we must conduct a comprehensive evaluation of students, and we must establish an evaluation system that objectively reflects the quality development of college students. At the same time, we must also emphasize social identity. On the other hand, it is necessary to establish an incentive mechanism: based on the results of the tutor's work over the past years, reward outstanding achievements and fully motivate the mentors and students.

\section{The policy of the school to carry out the guarantee of the tutorial system}

When the school scientific research management department formulates the relevant system, it requires teachers to apply for school-level and provincial-city projects, and students must be added to the research group to carry out scientific research in order to raise students' awareness of 
scientific research.

\section{Conclusion}

Science and technology innovation plays a crucial role in the development of the country and the nation. Raising undergraduates' scientific research and innovation ability has become an urgent task for colleges and universities. Through the scientific research tutoring system, allowing students to participate in practical research projects can significantly improve undergraduates' awareness of innovation and self-awareness. Inspiring students' awareness of scientific research and innovation, setting up related research courses, and perfecting evaluation mechanisms are all conducive to further improving the mechanism for cultivating students' innovative abilities, so as to promote the rapid economic development of our country.

\section{Acknowledgement}

Project Fund: Research Project of Teaching Reform in Higher Education Institutions in Jiangxi Province (No. JXJG-17-27-1)

\section{References}

[1] Wei-Wei H E. Study on the Innovation and Application of the Double Tutorial System in the international trade[J]. Economic Research Guide, 2013.

[2] Sha J, Zhou S, Zhang Y, et al. Research of Tutorial System in Developing the Innovative Ability of College Students[J]. Pharmaceutical Education, 2014.

[3] Ma C, Chen Y. Promoting the Construction of Top-notch Innovative Talents' Scientific Research Ability System with Tutorial System as the Starting Point[J]. Science Education Article Collects, 2015.

[4] Sha J, Zhou S, Zhang Y, et al. Research of Tutorial System in Developing the Innovative Ability of College Students[J]. Pharmaceutical Education, 2014.

[5] Ma C, Chen Y. Promoting the Construction of Top-notch Innovative Talents' Scientific Research Ability System with Tutorial System as the Starting Point[J]. Science Education Article Collects, 2015.

[6] Jing Z. Sharing "undergraduate tutorial system" platform, promote students' scientific research innovative practice[J]. Journal of Nanchang College of Education, 2013.

[7] Chen, Hong Ya, and L. Shi. "Design and Analysis of Innovation Survey in Scientific Research Institutions of Shaanxi Province." Scientific Management Research 46.46(2015):1242-9.

[8] Feng X, Zhao W, Liu C, et al. Investigation on Interdisciplinary Dual Tutorial System Construction in Improving Scientific Research Innovation Ability of Master Degree Candidate Majoring in Internal Medicine of TCM[J]. Western Journal of Traditional Chinese Medicine, 2016.

[9] Chen H Y, Shi L. Design and Analysis of Innovation Survey in Scientific Research Institutions of Shaanxi Province[J]. Scientific Management Research, 2015, 46(46):1242-9.

[10]Zhu Y, Yu Y, Wang H, et al. A research on the evaluation system of university scientific research performance based on collaborative innovation[J]. Science Research Management, 2016.

[11] Cheng B, Yang H, Wang L, et al. Research on the Cultivation Mode of Scientific Research Ability of Undergraduates Based on Tutorial System[J]. Science \& Technology Innovation Herald, 2017.

[12] Cheng B, Yang H, Wang L, et al. Research on the Cultivation Mode of Scientific Research Ability of Undergraduates Based on Tutorial System[J]. Science \& Technology Innovation Herald, 2017.

[13] Cheng B, Yang H, Wang L, et al. Research on the Cultivation Mode of Scientific Research Ability of Undergraduates Based on Tutorial System[J]. Science \& Technology Innovation 
Herald, 2017. 